\title{
BMJ Open Gender perspective of psychological discomfort during COVID-19 confinement among Spanish adult population: a cross-sectional study
}

\author{
Juan Gómez-Salgado (D) ,1,2 Sara Domínguez-Salas, ${ }^{3}$ \\ Carmen Rodríguez-Domínguez, ${ }^{3}$ Regina Allande-Cussó (D) , ${ }^{4}$ \\ Macarena Romero-Martín (D) , Carlos Ruiz-Frutos (D) ${ }^{1,2}$
}

To cite: Gómez-Salgado J, Domínguez-Salas S, RodríguezDomínguez C, et al. Gender perspective of psychological discomfort during COVID-19 confinement among Spanish adult population: a crosssectional study. BMJ Open 2021;11:e051572. doi:10.1136/ bmjopen-2021-051572

\section{- Prepublication history for} this paper is available online. To view these files, please visit the journal online (http://dx.doi. org/10.1136/bmjopen-2021051572).

Received 24 March 2021 Accepted 24 November 2021

\section{Check for updates}

(C) Author(s) (or their employer(s)) 2021. Re-use permitted under CC BY-NC. No commercial re-use. See rights and permissions. Published by BMJ.

${ }^{1}$ Department of Preventive Medicine and Public Health, Universidad de Huelva, Huelva, Spain

${ }^{2}$ Safety and Health Postgraduate Program, Espíritu Santo University, Guayaquil, Ecuador ${ }^{3}$ Department of Psychology, Universidad Loyola Andalucia, Sevilla, Spain

${ }^{4}$ Department of Nursing,

Universidad de Sevilla, Sevilla,

Spain

${ }^{5}$ Department of Nursing, Universidad de Huelva, Huelva, Spain

Correspondence to Dr Juan Gómez-Salgado; salgado@uhu.es

\section{ABSTRACT}

Objective COVID-19 disease has affected more than a hundred countries worldwide and has exposed the population to an increase in mental health problems. The objective of this study was to assess the emotional impact of the pandemic from a gender perspective, as well as to study the modulating variables of that impact.

Design A descriptive and cross-sectional study through the General Health Questionnaire scale and the Sense of Coherence (SOC) scale is developed.

Setting General population of Spain was the target of this study

Participants The sample consisted of 3801 adult subjects living in Spain, without diagnosis for Sars-Cov-2 virus infection during confinement.

Intervention Data collection was carried out using an online questionnaire, from 26 March 2020 to 26 April 2020.

Primary and secondary outcomes measures A sample profile description was obtained, regarding to the study variables. Later, a regression model was implemented in order to test the relationship between these variables, and to achieve a predictive model of psychological discomfort controlling the gender variable.

Results The results showed that women, as compared with men, had increased psychological discomfort during confinement ( $t=-12.877 ; p<0.001 ; d=0.470)$. In contrast, significantly higher scores were observed on the SOC scale ( $t=6.336 ; p<0.001 ; d=0.231$ ) in men, as compared with those obtained by women.

Conclusions Women have higher levels of psychological discomfort, increased concern about getting infected with COVID-19 and infecting others, as well as a lower level of SOC and perceived health. In addition, low levels of SOC predict greater concern about contagion and increased psychological discomfort.

\section{INTRODUCTION}

COVID-19 disease is caused by a new coronavirus and has affected more than a hundred countries worldwide since its first case in Wuhan, China, in November 2019. ${ }^{1}$ WHO declared the pandemic in March 2020, and
Strengths and limitations of this study

- The psychological discomfort during COVID-19 confinement has been described considering the gender variable.

- Future studies should increase the sample of male subjects with the aim of matching it in size to that of women.

- The number of children, care for dependents or type of work performed have not been included as variables.

according to the latest figures, it has infected 43540739 million people worldwide. ${ }^{2}$ The main global strategy adopted to curb the spread of the virus has been confinement. Spain also joined this measure, with the declaration of the State of Alarm on 14 March 2020, paralysing all work, academic and leisure activities, except for essential services. ${ }^{3}$

Lack of knowledge regarding the epidemiology of the new disease, as well as the high mortality and contagion rates associated, have led to an increase in concern about contagion in the population, thus mediating the onset of psychological distress. In addition, the exceptional situation of confinement has led to significant psychological implications, including depressive symptoms, emotional distress, insomnia, anxiety and feelings of loneliness. ${ }^{4-6}$ Additionally, quarantine due to COVID-19 pandemic had a negative impact on public mental health by rising posttraumatic stress disorder, which increased the subjective feeling of fear and reduced the sleeping quality of people under quarantine. ${ }^{7}$

On the other hand, the epidemiological evolution itself has also significantly increased the need for healthcare and assistance, both inside and outside the population's homes. Families with dependents who are also active 
working populations are one of the most affected groups by the confinement overload. Within families, women generally take responsibility for most of the burden of care of children and/or living dependents. ${ }^{7-9}$ As a result, women are likely to suffer a greater negative emotional impact during the COVID-19 confinement than men due to the enormous physical and mental care overload they might be taking on. ${ }^{10}{ }^{11}$ In this context, some studies have already reported on the differences between men and women in relation to the psychological impact of the pandemic and the presence of symptoms of anxiety and depression. ${ }^{12} 13$

In this context, the emotional impact of the COVID-19 pandemic should be studied from a social and gender perspective, putting women at the forefront of the response to the disease. ${ }^{14}$ On the one hand, $70 \%$ of care tasks fall on women, and in the 'state of alarm' and confinement and the consequent closure of schools, these increased in quantity. ${ }^{14}$ This situation, in addition to teleworking from home, caused an emotional overload in the Spanish population. On the other hand, of all the health professionals who assist those affected by the pandemic in hospitals, health centres, and residential facilities in Spain, $84 \%$ are women. ${ }^{15}$ Previous studies have revealed an association between the female gender of healthcare workers and the psychological impact caused by the COVID-19 pandemic. ${ }^{16}$ Women who work in healthcare have been identified to have more severe symptoms of depression, anxiety and insomnia, ${ }^{17}$ obsessive-compulsive symptoms, ${ }^{18}$ stress ${ }^{19}$ and post-traumatic stress syndrome ${ }^{20}$ than other healthcare professionals. Chew et al's study ${ }^{21}$ identified that healthcare workers, women, with COVID-19 symptoms also had a more serious deterioration in their mental health. In general, with regard to emotional well-being, there are gender differences, with women suffering the highest levels of psychological distress. ${ }^{12}$

On the other hand, the role of certain modulating or buffering variables of psychological impact in emergencies or catastrophes is known, such as coping strategies, resilience or personal and environmental resources and mechanisms. ${ }^{22-24}$ In this regard, Antonovsky ${ }^{25}$ proposed the salutogenic paradigm, which states that good emotional, psychic and somatic health is maintained by the dynamic ability of the human being to adapt to changes in their vital circumstances. ${ }^{25}$ Under this prism, Antonovsky, defined the Sense of Coherence (hereinafter referred to as SOC) as the ability of the human being to adaptively respond to stressful situations, a willingness to assess the circumstances of life as significant, predictable and manageable. ${ }^{26}$ In this sense, a higher level of SOC can improve coping and decrease anxiety levels. ${ }^{27}$

In the face of a pandemic such as the one at hand, it would be necessary to address both its impact on the mental health of citizens and the possible mediating characteristics of factors such as the SOC, highly related with resilience and psychological well-being, in order to show a more complete view of the confrontation of such stressful circumstances among men and women so as to tackle the hypothesis that restrictive measures could have had a greater negative impact on the female group. Thus, it was hypothesised that women would experience higher levels of psychological discomfort during confinement as compared with men, with other variables mediating and moderating the relationship. For this reason, the general objective of this study was to analyse the relationship between gender and psychological discomfort in the first month of the pandemic and population confinement in Spain due to the COVID-19 disease, as well as the role played in this relationship by other variables such as the SOC and concern for contagion.

\section{METHODS \\ Design}

A descriptive cross-sectional study was carried out using the selective method, according to the classification proposed by Argimón, ${ }^{28}$ through a questionnaire.

\section{Participants}

The study population, as well as the inclusion criteria of the sample, was: Spanish adult population, living in Spain, who had not received any diagnosis, neither negative nor positive, for Sars-Cov-2 virus infection. This criterion was imperative to ensure the correct assessment of the fear of infection. Initially 4139 questionnaires were collected, and after applying the inclusion criteria, 3801 questionnaires were finally selected. Those that were not fully completed or did not meet the inclusion criteria were discharged. The final sample consisted of 3801 participants, $72.8 \%$ women. Ages ranged from 18 to 79 years old $(\mathrm{M}=40.12 ; \mathrm{SD}=13.36)$. The most common marital status was married or living as a couple $(56.5 \%)$, followed by single $(35.3 \%)$. In relation to the level of studies, $46 \%$ of the participants had university studies (diploma, bachelor's degree or university degree) while $29.2 \%$ held a postgraduate, master's and/or doctoral level of education. Finally, and in view of the employment situation, $22.4 \%$ were in telework mode, $41.5 \%$ worked away from home, and $36.1 \%$ were inactive at work.

\section{Variables and measuring instruments}

The following study variables were identified, as well as the measuring instruments described:

Sociodemographic variables: gender, age, marital status, level of studies, province of residence and employment situation were measured variables.

General Health Questionnaire $(\mathrm{GHQ}-12)^{29}$ : Selfadministered scale composed of 12 items that allow to assess the state of mental health or psychological discomfort, as well as to detect psychiatric morbidity. Each item presents four response options, scoring the first two response options with zero points, and with one point the remaining ones. The total score on the scale could range from 0 to 12 points (the higher the obtained score, the greater the psychological discomfort the participant 
presents). This instrument has demonstrated adequate psychometric properties in the Spanish population, even in people over 65 years of age ${ }^{29}$ In this study, the internal consistency index (Cronbach Alpha) obtained was $\alpha=0.85$.

SOC- $13^{24}$ in its Spanish version. ${ }^{26}$ Self-managed scale of 13 items with seven semantic differential points, that evaluates the SOC as a variable related to facing traumatic situations. ${ }^{30}$ It is necessary to invert items 1, 2, 3, 7 and 10 for correction. The total score of the scale ranges from 13 to 91 points, and the scores are placed in the way where the higher the score, the higher its position in the scale, showing the person has a higher SOC. The internal consistency index obtained in this study was $\alpha=0.80$.

Concern about contagion and concern to infect others: two ad hoc items were designed with Likert-like response scales ranging from 1 ('I'm not worried about anything') to 10 ('I'm very concerned').

Self-perceived health: an ad hoc item was designed ('How have you perceived your health in the last 2 weeks?'), which was evaluated by a scale of five response options, from 1 ('very bad') to 5 ('very good'), following Idler and Benyamini's ${ }^{31}$ proposal and adapting the item according to subsequent research on pandemics. ${ }^{32} 33$

\section{Procedure}

Data collection was carried out through an online questionnaire, using the Qualtrics Survey Platform (Qualtrics: Provo, Utah, USA). The snowball method was used to select the sample by contacting academic and scientific bodies for the dissemination of the study, as well as promoting participation through online social networks and the press. Following the State of Alarm decreed in Spain due to the COVID-19 pandemic, and the subsequent population confinement that began on 14 March 2020, data collection for this study was implemented from 26 March 2020 to 26 April 2020.

\section{Ethical considerations}

The Declaration of Helsinki, ratified in 2013, was taken into account ${ }^{34}$ to conduct this research. Participants were required to explicitly provide informed consent prior to their participation, which was voluntary and confidential.
Data collection was done in accordance with current laws on the protection of personal data.

\section{Patient and public involvement}

It was not appropriate or possible to involve patients or the public in the design, or conduct, or reporting, or dissemination plans of our research.

\section{Data analysis}

The data analysis was carried out with the SPSS statistical programme V. $26^{35}$ and the macro PROCESS. ${ }^{36}$ An initial descriptive analysis was performed by calculating the mean scores and typical deviations of the variables. Differences by gender were examined by applying Student's $\mathrm{T}$ for independent samples (Cohen's $\mathrm{d}=0.20$, small; .50, intermediate; $>0.80$, large). Finally, multiple linear regression analyses were performed to determine the predictors of psychological discomfort $\left(\mathrm{R}^{2}=0.01\right.$, small, 0.10 , median, $>0.25$, large). To do this, the macro PROCESS was used to check a moderate mediation predictive model that includes the rest of the variables that in preliminary analyses show an association with psychological discomfort. The model was designed by the authors according to Hayes indications. ${ }^{37}$ SEs were generated using the covariance matrix estimator including HC4 heteroscedasticity ${ }^{38}$ and the number of extracted samples per resampling; for confidence intervals, it was 10000 .

\section{RESULTS}

\section{Preliminary analysis}

Table 1 shows the descriptive statistics of the study variables, with statistically significant gender differences observed in all cases. Women as compared with men had increased psychological discomfort during confinement $(\mathrm{M}=5.35 ; \mathrm{SD}=3.30 ; \mathrm{t}=-12.877 ; \mathrm{p}<0.001 ; \mathrm{d}=0.470)$. In addition, significantly higher scores were observed in SOC among men $(\mathrm{M}=63.76$; $\mathrm{SD}=12.37$; $\mathrm{t}=6.336$; $\mathrm{p}<0.001$; $\mathrm{d}=0.231$ ), as compared with those obtained by women. Slight gender differences were also found regarding concern about COVID-19 sickness and in the concern to infect other people in case of contagion, being higher among women in both items. However, considering the

Table 1 Descriptive statistics of the total sample by gender

\begin{tabular}{|c|c|c|c|c|c|c|}
\hline & \multicolumn{2}{|l|}{$\begin{array}{l}\text { Total } \\
(\mathrm{N}=3801)\end{array}$} & \multirow{2}{*}{$\begin{array}{l}\begin{array}{l}\text { Males } \\
(n=1032)\end{array} \\
M(S D)\end{array}$} & \multirow{2}{*}{$\begin{array}{l}\text { Females } \\
(\mathrm{n}=2769) \\
M(S D)\end{array}$} & \multirow[b]{2}{*}{$T$ (p value) } & \multirow[b]{2}{*}{ ES } \\
\hline & $M$ (SD) & Min-Max & & & & \\
\hline SOC & $61.64(12.64)$ & $19-91$ & $63.76(12.37)$ & $60.85(12.65)$ & $6.336(<0.001)$ & 0.231 \\
\hline Concern for infection & $7.37(2.42)$ & $1-10$ & $7.13(2.48)$ & $7.46(2.39)$ & $-3.847(<0.001)$ & 0.137 \\
\hline
\end{tabular}

ES, effect size (Cohen's d); GHQ-12, General Health Questionnaire 12; SOC, Sense of Coherence. 
Table 2 Mediators and moderators in the relationship between gender and psychological distress (GHQ-12) in participants without diagnostic tests for COVID-19 $(n=3801)$

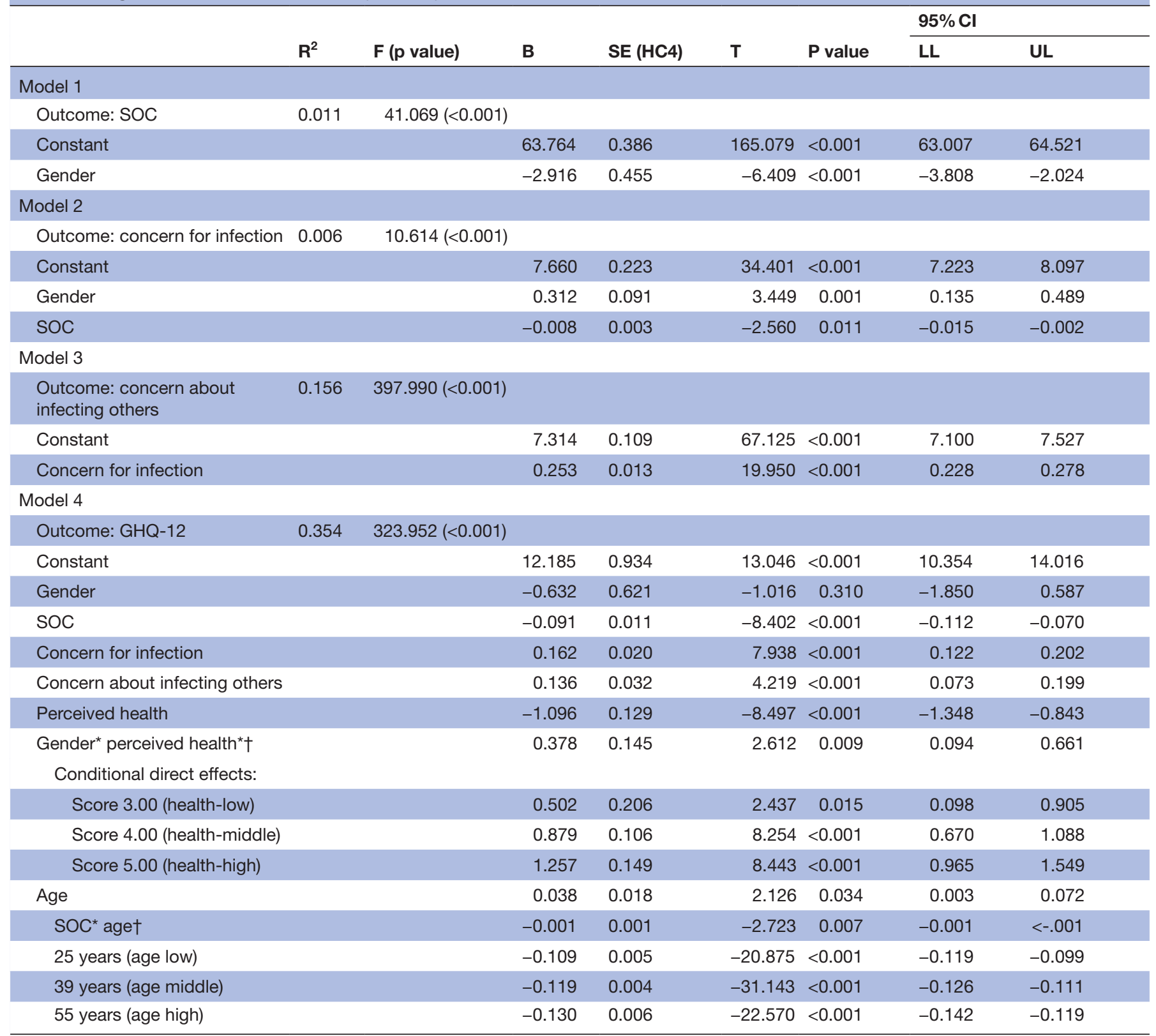

*Johnson-Neyman significance region=2.844.

$\dagger$ There are no statistical significance transition points within the observed range of the moderator found using the Johnson-Neyman method. GHQ-12, General Health Questionnaire-12; LL, lower limit; SOC, Sense of Coherence; UL, upper limit.

perceived health, the observed mean score was significantly higher among male participants than among women.

\section{Gender and psychological discomfort: moderate mediation model}

Tables 2 and 3, figure 1 show the moderate mediation model resulting from various linear regression analyses, identifying direct and indirect effects on the psychological discomfort variable by the rest of the study variables.

Considering model 1, a statistically significant main effect of gender on SOC was observed. Similarly, using model 2, the main effect of gender and SOC for the output variable concern about contagion was established. Model 3 determined the main effect of concern about contagion on the variable concern about infecting others. Finally, model 4, which identifies the predictors of psychological discomfort, determined that $35 \%$ of the variance observed in that variable was explained by the following main effects and interaction effects: SOC, concern about contagion, concern about infecting others, perceived health, age, gender*perceived health and SOC*age. The differences between men and women in the scores obtained in 
Table 3 Indirect effects in the relationship between gender and psychological distress (GHQ-12) in participants without diagnostic tests for COVID-19 $(n=3801)$

\begin{tabular}{|c|c|c|c|c|c|}
\hline & \multirow{2}{*}{$\begin{array}{l}\text { Index of moderated } \\
\text { mediation }\end{array}$} & \multirow[b]{2}{*}{ B } & \multirow{2}{*}{$\begin{array}{l}\text { BootSE } \\
\text { (HC4) }\end{array}$} & \multicolumn{2}{|l|}{$95 \% \mathrm{Cl}$} \\
\hline & & & & BootLL & BootUL \\
\hline (1) Gender $\rightarrow$ SOC*Age $\rightarrow$ GHQ & 0.002 & & 0.001 & 0.001 & 0.004 \\
\hline 39 years (age-middle) & & 0.346 & 0.054 & 0.237 & 0.454 \\
\hline 55 years (age-high) & & 0.380 & 0.060 & 0.258 & 0.499 \\
\hline (3) Gender $\rightarrow$ SOC $\rightarrow$ Concern for infection $\rightarrow$ GHQ-12 & & 0.004 & 0.002 & 0.001 & 0.008 \\
\hline $\begin{array}{l}\text { (4) Gender } \rightarrow \text { Concern for infection } \rightarrow \text { Concern about } \\
\text { infecting others } \rightarrow \text { GHQ-12 }\end{array}$ & & 0.011 & 0.004 & 0.004 & 0.020 \\
\hline $\begin{array}{l}\text { (5) Gender } \rightarrow \text { SOC } \rightarrow \text { Concern for infection } \rightarrow \text { Concern } \\
\text { about infecting others } \rightarrow \text { GHQ-12 }\end{array}$ & & 0.001 & 0.001 & 0.001 & 0.002 \\
\hline
\end{tabular}

BootLL, lower limit; BootSE (HC4), heteroscedasticity-consistent covariance matrix estimators HC4; BootUL, upper limit; GHQ-12, General Health Questionnaire-12; SOC, Sense of Coherence.

the GHQ-12 became more evident when perceived health was high, with women presenting the greatest psychological discomfort in this regard (figure 2).

One way of indirect effect of gender on psychological discomfort would be through SOC*Age interaction. As table 3 shows, the CI for the moderate mediation index did not contain the zero value $(\beta=0.002 ; \mathrm{SE}=0.001$, $95 \%$ CI 0.001 to 0.004 ), suggesting the existence of differences in the indirect effects among the different levels of the moderator. As shown in figure 3, the effect of gender on psychological discomfort is greater as the age of the participant increases, exerting its maximum effect at the age of 55 .
Other way of gender effect on psychological discomfort is indirectly established through concern about contagion $(\beta=0.050 ; \mathrm{SE}=0.016,95 \% \mathrm{CI} 0.021$ to 0.085$)$. Women were more concerned about spreading the virus themselves, and this increased concern raised higher rates of psychological discomfort.

The third route of indirect effect links gender with SOC and concern for contagion until reaching psychological discomfort $(\beta=0.004$; $\mathrm{SE}=0.002,95 \%$ CI 0.001 to 0.008$)$. In this case, being a woman meant getting lower scores on SOC. Both the fourth $(\beta=0.011 ; \mathrm{SE}=0.004,95 \% \mathrm{CI}$ 0.004 to 0.020$)$ ) and the fifth way $(\beta=0.001 ; \mathrm{SE}=0.001$, $95 \%$ CI 0.001 to 0.002 ) introduce the variable concern

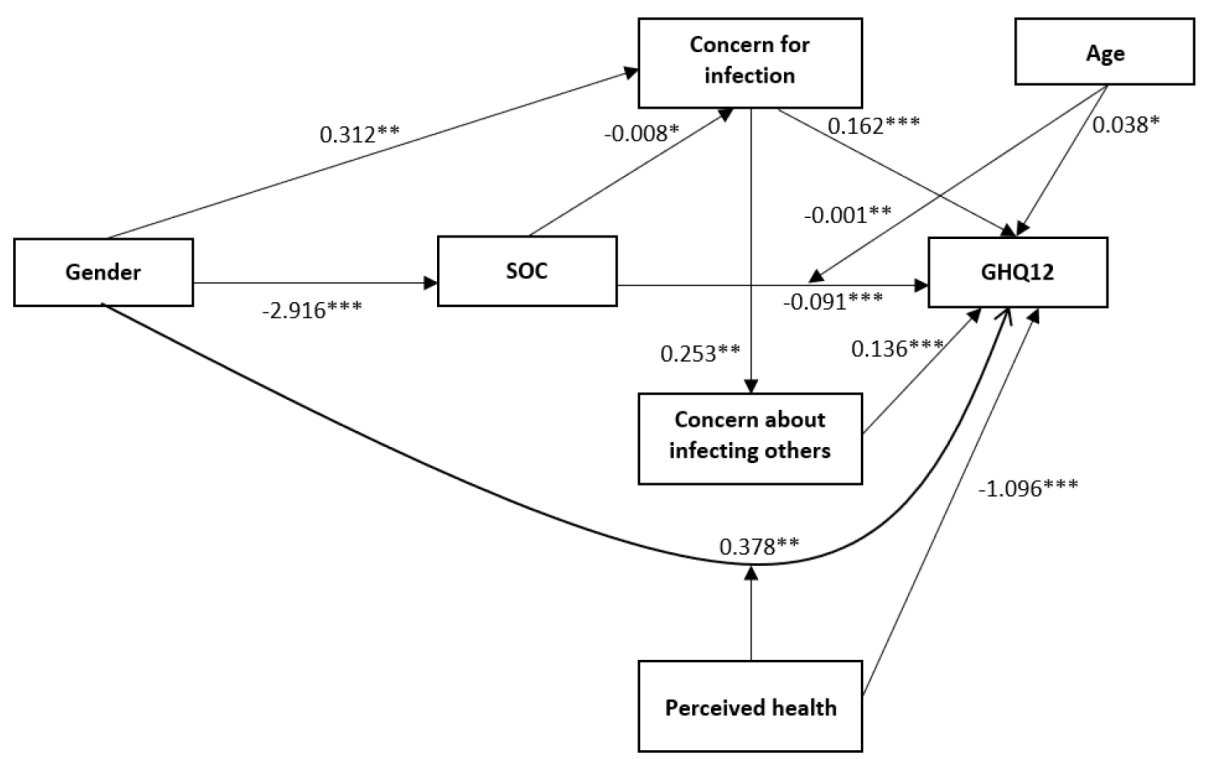

Figure 1 Moderated mediation model. Direct and indirect effects (unstandardised regression coefficients) of Gender, SOC, concern for infection, concern about infecting others, perceived health and age on psychological distress (GHQ-12) in participants without diagnostic tests for COVID-19 $(n=3801)$. ${ }^{*} \mathrm{P}<0.05 ;{ }^{* \star} \mathrm{p}<0.01$; ${ }^{\star \star \star} \mathrm{p}<0.001$. GHQ-12, General Health Questionnaire-12; SOC, Sense of Coherence. 


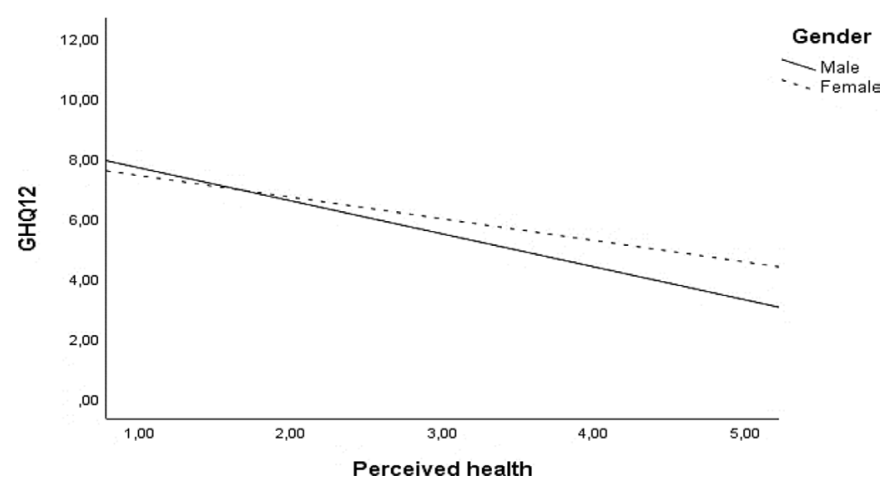

Figure 2 Moderator effect of perceived health in the relationship between gender and psychological distress (GHQ-12). GHQ-12, General Health Questionnaire-12.

about infecting others in the indirect effect of gender on psychological discomfort.

By completing the overall interpretation of the model, it would be added that a greater concern of the person about spreading the virus, which happens especially in women, predicts a greater concern about infecting others and, in turn, greater psychological discomfort.

\section{DISCUSSION}

The main objective of this study was to analyse the relationship between gender and psychological discomfort at the beginning of the COVID-19 pandemic in Spain in a widespread situation of population confinement such as that which took effect in March and April 2020.

The results have shown that women have higher levels of psychological discomfort, increased concern about getting infected with COVID-19 and infecting others, as well as lower SOC and perceived health, as compared with participating men.

Women's tendency to develop emotional disorders is described in the mental health and public health report of the Carlos III Institute of Health. ${ }^{15}$ In addition, a recent study by Bacigalupe $e t a l^{39}$ also suggests that unequal living conditions between the two genders and the possible overdiagnosis and medicalisation of women's mental health could explain this trend. Lau et $a l^{40}$ reported an

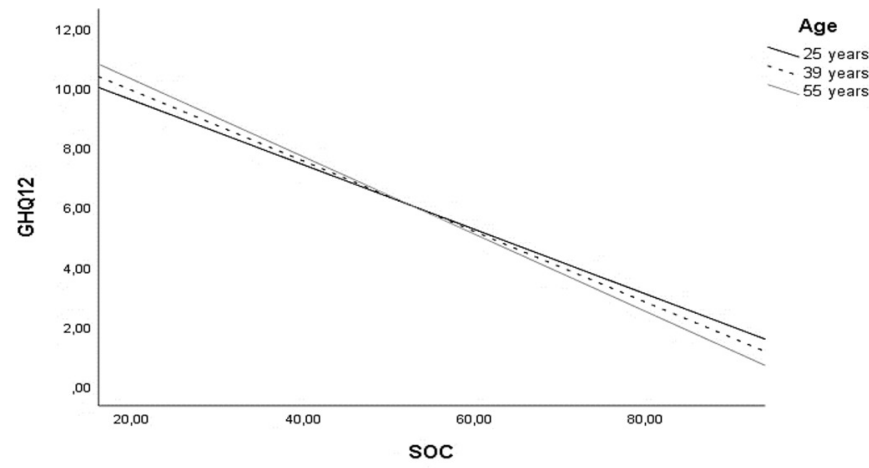

Figure 3 Moderating effect of age in the relationship between SOC and psychological distress (GHQ-12). GHQ-12, General Health Questionnaire-12; SOC, Sense of Coherence. increased risk of psychological discomfort associated with the female gender during other epidemics. Thus, they concluded that women had a higher level of distress with respect to the H1N1 virus epidemic and an increased concern about contracting it. ${ }^{40}$ Recent publications also warn of increased psychological impact and deterioration of mental health among women during the COVID-19 pandemic, with higher levels of anxiety and general psychological discomfort observed in this population group. ${ }^{17-43}$ In the same way, a study among Chinese population concluded that women had a higher incidence of acute posttraumatic stress disorder during the COVID-19 outbreak. ${ }^{44}$

For this study, SOC was identified as a modulating variable of psychological discomfort, as it encompasses not only resilience but also the ability of human beings to adaptively respond to stressful situations, a willingness to assess life circumstances as significant, predictable and manageable. ${ }^{26}{ }^{27}$ It is therefore a more comprehensive construct than the mere consideration of coping or resilience as study variables. Likewise, concern about contagion and self-perception of health were also identified as modulating variables, as COVID-19 is a new disease whose epidemiological evolution tended to high mortality and high rates of contagion during the initial confinement, both situations that accelerated the emergence of concern about contagion in the population and the decrease in perceived health levels. ${ }^{4-6}$ In this sense, the SOC, recognised as a capacity that people have and that allows us to cushion the effects of stress on our lives, ${ }^{45}$ has been identified in this study as a predictor of psychological discomfort and, in addition, a mediating variable between this discomfort and gender. Thus, lower SOC has been shown among the women in this study, which supports that their level of psychological discomfort is higher than that one experienced by participating men. Carmel $e t a l^{46}$ have already identified that women and men are affected differently by stressors and make differentiated use of their coping resources. ${ }^{46}$ In addition, the results of this research are consistent with the reality of the healthcare profile in our country, a task that falls mainly on the female gender, with women representing $86.4 \%$ of caregivers in Spain, a group that has shown lower levels of SOC. ${ }^{47}$

Previous studies among Spanish general population have also identified a high percentage $(71.98 \%)$ of participants with psychological distress, with a higher percentage in women $(79.60 \%) .{ }^{48}$ In addition, low levels of SOC corresponded to the highest percentages of distress $(86.3 \%) .{ }^{49}$ Therefore, the results obtained in this study confirmed the psychological distress in the general Spanish population, although those with high levels of SOC, in this study is the group of men, present higher levels of emotional well-being.

Official statistics have already indicated for years that women have a worse perception of their health situation as compared with men, a difference that is more pronounced as the social status decreases. ${ }^{50}$ The results 
of this study follow this same line, and describe a worse perception of health among the women in the sample. Similarly, data point to a lower effect of confinement on the psychological well-being of people among those who perceive their overall health more positively. In this sense, perceived health acts as a mediator of the relationship between gender and psychological discomfort. Thus, when comparing women and men with high perception of health, it is observed that women in this group would have a worse psychological adjustment with respect to men. On the contrary, when both genders have lower perceived health, men have lower levels of psychological well-being. These results could clarify the contradiction observed between studies that indicate greater harm to women's mental health in the current COVID-19 pandemic ${ }^{51}$ and those that indicate higher suffering for men (men's conditions) in other past scenarios, such as the SARS virus epidemic in China in $2003 .{ }^{52}$

Other interesting findings in this work have to do with the incidence of age and concern about getting infected and/or infecting others. Taylor et $a \tilde{l}^{\tilde{3}}$ described that the younger adult population had increased psychological discomfort during Australia's equine influenza epidemic of $2007 .{ }^{53}$ In contrast, Lau et a $t^{40}$ concluded that high levels of psychological discomfort were found in the older adult population. ${ }^{39}$ On the current pandemic, there is evidence of worse results in mental health variables among young people ${ }^{5455}$ while other results do not show differences in this regard depending on age. ${ }^{404256}$ Given the divergence of the observed results, this study could shed light in this regard. Thus, preliminarily, data suggest the existence of an inverse relationship between age and psychological discomfort. However, this should be interpreted by the interaction observed between age and SOC. In this way, psychological discomfort would be higher among the youngest participants of the sample when comparing participants with high levels of SOC. In contrast, older people would experience greater psychological discomfort in cases where the SOC reaches low levels. Therefore, high SOC could be considered a protective factor against the psychological effect of confinement in older people. In the case of younger population, it appears that psychological discomfort would be related to the impossibility of carrying out leisure activities, meeting friends or going out. ${ }^{48}$

Following the results of this research, it has been observed that younger participants would be less concerned about getting this variant of coronavirus, a conclusion that is in line with Barber et $a \tilde{l}^{\tilde{7}}$ study, who also argue that adolescents and young male adults had less concern about the disease than their older congeners. Our results highlight that concern about contagion would be a predictor of psychological discomfort, while acting as a mediator in the effect of SOC on discomfort. In other words, a worse SOC predicts greater concern about contagion and this, in turn, causes greater psychological discomfort. Although younger participants are less concerned about COVID-19 disease, they would be more concerned about the possibility of spreading the virus to others, as compared with older ones. It can be inferred from these results that younger adults are aware of the scope of the disease for certain groups considered at risk, for example, because of their age or because they suffer from other previous pathologies, and this burden of responsibility could result in a greater impact on their mental health situation.

In relation to the limitations of this study, it should be mentioned that $78.2 \%$ of the sample was of the female gender. These data may represent a bias in the interpretation of significant gender differences regarding the level of psychological discomfort. Nevertheless, the subsamples were quite large, exceeding one thousand cases in each gender, so the statistical analysis used, and its subsequent interpretation could be plausible. It should also be noted that the use of questionnaires as a method for data collection could affect the quality of the data and is also a limitation. However, the COVID-19 pandemic situation and the restrictions imposed by the government did not allow the use of techniques such as interviews.

Future studies should increase the sample of male subjects with the aim of matching it in size to that of women. Likewise, sociodemographic variables such as number of children, care for dependents or type of work performed have not been considered. In future work, it would be interesting to know how the presence of women in these areas is distributed in the situation of COVID-19 pandemic, as well as including perceived social support as another modulating variable of psychological distress.

\section{CONCLUSIONS}

This study highlights a greater effect of confinement and the circumstances surrounding the COVID-19 pandemic on the mental health level of women living in Spain. Compared with men, women have higher levels of psychological discomfort, increased concern for getting infected and infecting others, as well as lower SOC and perceived health. This study has shown that these variables work by mediating and moderating the relationship between gender and psychological discomfort, providing a more comprehensive analysis of the differential effect of the pandemic on men and women, and complementing the evidence gathered so far on gender and mental health in COVID-19 studies. In addition, it also reflects that women, a group at the forefront of childcare, the elderly and dependents, are suffering greatly from the effects of this health and social crisis.

Correction notice This article has been corrected since it first published. Affiliations have been updated.

Contributors Conceptualisation, JGS, SDS, CRD, RAC, MRM and CRF; Data curation, JGS, SDS, CRD, RAC, MRM and CRF; Formal analysis, JGS, SDS, CRD, RAC, MRM and CRF; Investigation, JGS, SDS, CRD, RAC, MRM and CRF; Methodology, JGS, SDS, CRD, RAC, MRM and CRF; Project administration, JGS, SDS, MRM and CRF; Resources, JGS, CRD, RAC, MRM and CRF; Software, SDS, CRD and RAC; Supervision, JGS, MRM and CRF; Validation, SDS, CRD, RAC and MRM; Visualisation, 
JGS, MRM and CRF; writing-original draft, JGS, SDS, CRD, RAC, MRM and CRF; Writing-review and editing, SDS, MRM and CRF; Guarantor, JGS.

Funding The authors have not declared a specific grant for this research from any funding agency in the public, commercial or not-for-profit sectors.

Competing interests None declared.

Patient and public involvement Patients and/or the public were not involved in the design, or conduct, or reporting, or dissemination plans of this research.

Patient consent for publication Not applicable.

Ethics approval This study involves human participants and was approved by Research Ethics Committee of Huelva, belonging to the Regional Ministry of Health of Andalusia (PI 036/20)

Provenance and peer review Not commissioned; externally peer reviewed.

Data availability statement Data are available on reasonable request. Data are available on reasonable request to correpondence author.

Open access This is an open access article distributed in accordance with the Creative Commons Attribution Non Commercial (CC BY-NC 4.0) license, which permits others to distribute, remix, adapt, build upon this work non-commercially, and license their derivative works on different terms, provided the original work is properly cited, appropriate credit is given, any changes made indicated, and the use is non-commercial. See: http://creativecommons.org/licenses/by-nc/4.0/.

\section{ORCID iDs}

Juan Gómez-Salgado http://orcid.org/0000-0001-9053-7730

Regina Allande-Cussó http://orcid.org/0000-0001-8325-0838

Macarena Romero-Martín http://orcid.org/0000-0003-3022-3339

Carlos Ruiz-Frutos http://orcid.org/0000-0003-3715-1382

\section{REFERENCES}

1 Russell CD, Millar JE, Baillie JK. Clinical evidence does not support corticosteroid treatment for 2019-nCoV lung injury. The Lancet 2020;395:473-5.

2 John Hopkins Coronavirus Research Center [internet]. COVID-19 Dashboard by the center for systems science and engineering (CSSE) at Johns Hopkins University (JHU. USA: Johns Hopkins University (JHU), 2020. https://coronavirus.jhu.edu/map.html

3 Gobierno de España. España: real Decreto 463/2020 de 14 de marzo POR El se declara Estado de Alarma, 2020. Available: https://www. boe.es/buscar/act.php?id=BOE-A-2020-3692 [Accessed 15 Oct 2020].

4 Brooks SK, Webster RK, Smith LE, et al. The psychological impact of quarantine and how to reduce it: rapid review of the evidence. The Lancet 2020;395:912-20.

5 Bu F, Steptoe A, Fancourt D. Loneliness during lockdown: trajectories and predictors during the COVID-19 pandemic in 35,712 adults in the UK. medRxiv 2020.

6 Lima CKT, Carvalho PMdeM, Lima IdeAAS, et al. The emotional impact of coronavirus 2019-nCoV (new coronavirus disease). Psychiatry Res 2020;287:112915.

7 Wu L, Guo X, Shang Z, et al. China experience from COVID-19: mental health in mandatory quarantine zones urgently requires intervention. Psychol Trauma 2020;12:S3-5.

8 Chesley N. What does it mean to be a "breadwinner" mother? J Fam Issues 2017;38:2594-619.

9 Manzo LKC, Minello A. Mothers, childcare duties, and remote working under COVID-19 lockdown in Italy: cultivating communities of care. Dialogues Hum Geogr 2020;10:120-3.

10 Blaskó Z, Papadimitriou E, Manca AR. How will the COVID-19 crisis affect existing gender divides in Europe? Luxembourg: Publications Office of the European Union, 2020

11 Wenham C, Smith J, Morgan R, et al. COVID-19: the gendered impacts of the outbreak. Lancet 2020;395:846-8.

12 González-Sanguino C, Ausín B, Castellanos Miguel Ángel, et al. Mental health consequences during the initial stage of the 2020 coronavirus pandemic (COVID-19) in Spain. Brain Behav Immun 2020;87:172-6.

13 Özdin S, Bayrak Özdin Şükriye. Levels and predictors of anxiety, depression and health anxiety during COVID-19 pandemic in Turkish Society: the importance of gender. Int J Soc Psychiatry 2020;66-504-11.

14 Instituto de la Mujer y para la Igualdad de Oportunidades, Ministerio de Igualdad del Gobierno de España. La perspectiva de género, esencial en La respuesta a la COVID-19, 2020. Available: https:// www.inmujer.gob.es/diseno/novedades/impacto_de_genero_del covid_19_(uv) [Accessed 15 Oct 2020].

15 Instituto de Salud Carlos III, Ministerio de Sanidad del Gobierno de España. Evolución de la pandemia POR COVID-19, 2020. Available: https://cnecovid.isciii.es/covid19/ [Accessed 15 Oct 2020].

16 Luo M, Guo L, Yu M, et al. The psychological and mental impact of coronavirus disease 2019 (COVID-19) on medical staff and general public - A systematic review and meta-analysis. Psychiatry Res 2020;291:113190.

17 Lai J, Ma S, Wang Y, et al. Factors associated with mental health outcomes among health care workers exposed to coronavirus disease 2019. JAMA Netw Open 2020;3:e203976.

18 Zhang W-R, Wang K, Yin L, et al. Mental health and psychosocial problems of medical health workers during the COVID-19 epidemic in China. Psychother Psychosom 2020;89:242-50.

19 Mazza C, Ricci E, Biondi S, et al. A nationwide survey of psychological distress among Italian people during the COVID-19 pandemic: immediate psychological responses and associated factors. Int J Environ Res Public Health 2020;17:3165.

20 Liu N, Zhang F, Wei C, et al. Prevalence and predictors of PTSS during COVID-19 outbreak in China hardest-hit areas: gender differences matter. Psychiatry Res 2020;287:112921.

21 Chew NWS, Lee GKH, Tan BYQ, et al. A multinational, multicentre study on the psychological outcomes and associated physical symptoms amongst healthcare workers during COVID-19 outbreak. Brain Behav Immun 2020;88:559-65.

22 Arciniega J. La Resiliencia Comunitaria en Situaciones Catastroficas Y de Emergencia. Internacional Journal of Developmental and Educational Psychology 2010;1:687-93.

23 Benight CC, Harper ML. Coping self-efficacy perceptions as a mediator between acute stress response and long-term distress following natural disasters. J Trauma Stress 2002;15:177-86.

24 Cavanillas M, Martín-Barrajón P. Psicología de urgencias Y emergencias: ¿mito O realidad? Lez Artis AD hoc. International Scientific Journal 2012;1:27-32.

25 Antonovsky A. Unraveling the mystery of health. How people manage stress and stay well. San Francisco: Jossey-Bass, 1987.

26 Virués-Ortega J, Martínez-Martín P, del Barrio JL, et al. Validación transcultural de la Escala de Sentido de Coherencia de Antonovsky (OLQ-13) en ancianos mayores de 70 años. Medicina Clínica 2007:128:486-92 sci-hub.do/10.1157/13100935

27 Brizzio A, Carreras A. Variables salugénicas Y SU relación Con Los sucesos de vida Revista Iberoamericana de Diagnóstico y Evaluación - e Avaliação Psicológica. , 2007: 1, 83-99. https://www.redalyc.org/ articulo.oa? id=459645446006

28 Argimón J. Métodos de investigación clínica Y epidemiológica. 4th edn. España: ElSevier, 2012.

29 Goldberg DP, Gater R, Sartorius N, et al. The validity of two versions of the GHQ in the who study of mental illness in general health care. Psychol Med 1997;27:191-7.

30 Lizarbe M, Guillén F, Aguinaga I. Validación del Cuestionario de Orientación a la Vida (OLQ-13) de Antonovsky en Una muestra de estudiantes universitarios en Navarra. Anales Sis San Navarra 2020;39:248 http://scielo.isciii.es/scielo.php?script=sci_arttext\&pid= S1137-66272016000200006\&lng=es

31 Idler EL, Benyamini Y. Self-rated health and mortality: a review of twenty-seven community studies. J Health Soc Behav 1997;38:21-37

32 Hawryluck L, Gold WL, Robinson S, et al. SARS control and psychological effects of quarantine, Toronto, Canada. Emerg Infect Dis 2004;10:1206-12.

33 Goulia P, Mantas C, Dimitroula D, et al. General hospital staff worries, perceived sufficiency of information and associated psychological distress during the $\mathrm{A} / \mathrm{H} 1 \mathrm{~N} 1$ influenza pandemic. BMC Infect Dis 2010;10:322.

34 Barrios I, Anido V, Morera M. Declaración de Helsinki: cambios Y exégesis. Rev Cubana Salud Pública 2016;42 http://www. revsaludpublica.sld.cu/index.php/spu/article/view/597

35 IBM Corp. IBM SPSS statistics for windows, version 26.0. Armonk, NY: IBM Corp, 2019.

36 Hayes JR. Modeling and remodeling writing. Writ Commun 2012;29:369-88.

37 Hayes AF. Partial, conditional, and moderated moderated mediation: quantification, inference, and interpretation. Commun Monogr 2018;85:4-40.

38 Hayes AF, Cai L. Using heteroskedasticity-consistent standard error estimators in OLS regression: an introduction and software implementation. Behav Res Methods 2007;39:709-22.

39 Becigalupe A, Cabezas A, Baza M. El género como determinante de la salud mental Y SU medicalización. Informe SESPAS 2020. Gaceta Sanitaria 2020;34:61-7. 
40 Lau JTF, Griffiths S, Choi KC, et al. Avoidance behaviors and negative psychological responses in the general population in the initial stage of the H1N1 pandemic in Hong Kong. BMC Infect Dis 2010;10:139 http://www.biomedcentral.com/1471-2334/10/139

41 Leung GM, Ho L-M, Chan SKK, et al. Longitudinal assessment of community psychobehavioral responses during and after the 2003 outbreak of severe acute respiratory syndrome in Hong Kong. Clin Infect Dis 2005;40:1713-20.

42 Mazza C, Colasanti M, Ricci E, et al. The COVID-19 outbreak and psychological distress in healthcare workers: the role of personality traits, attachment styles, and sociodemographic factors. Sustainability 2021;13:4992.

43 Rodríguez C, Carrascal B, Durán M. Anxiety and intimate relationships in times of Lockdown due to COVID-19. Psychological Trauma: Theory, Research, Practice and Policy 2020.

44 Sun L, Sun Z, Wu L, et al. Prevalence and risk factors for acute posttraumatic stress disorder during the COVID-19 outbreak. J Affect Disord 2021;283:123-9.

45 Fernández E, Liébana C, Morán C. Relación entre El sentido de coherencia Y El cansancio emocional en estudiantes Universitario. Psychology, Society, \& Education 2017;9:393-403.

46 Carmel S, Anson O, Levenson A, et al. Life events, sense of coherence and health: gender differences on the Kibbutz. Soc Sci Med 1991;32:1089-96.

47 López-Martínez C, Frías-Osuna A, del-Pino-Casado R. Sentido de coherencia $Y$ sobrecarga subjetiva, ansiedad $Y$ depresión en personas cuidadoras de familiares mayores. Gac Sanit 2019;33:185-90.

48 Ruiz-Frutos C, Ortega-Moreno M, Allande-Cussó R, et al. Health-related factors of psychological distress during the COVID-19 pandemic among non-health workers in Spain. Saf Sci 2021;133:104996.
49 Ruiz-Frutos C, Ortega-Moreno M, Allande-Cussó R, et al. Sense of coherence, engagement, and work environment as precursors of psychological distress among non-health workers during the COVID-19 pandemic in Spain. Saf Sci 2021;133:105033.

50 Ministerio de Sanidad. Consumo Y Bienestar del Gobierno de España. Encuesta Nacional de Salud ENSE España, 2017. Available: https://www.mscbs.gob.es/estadEstudios/estadisticas/ encuestaNacional/encuestaNac2017/SALUD_MENTAL.pdf [Accessed 15 Oct 2020].

51 Gustavsson J, Beckman L. Compliance to recommendations and mental health consequences among elderly in Sweden during the initial phase of the COVID-19 Pandemic-A cross sectional online survey. Int J Environ Res Public Health 2020;17:5380.

52 Mihashi M, Otsubo Y, Yinjuan X, et al. Predictive factors of psychological disorder development during recovery following SARS outbreak. Health Psychol 2009;28:91-100.

53 Taylor MR, Agho KE, Stevens GJ, et al. Factors influencing psychological distress during a disease epidemic: data from Australia's first outbreak of equine influenza. BMC Public Health 2008;8:347.

54 Huang Y, Zhao N. Generalized anxiety disorder, depressive symptoms and sleep quality during COVID-19 outbreak in China: a web-based cross-sectional survey. Psychiatry Res 2020;288:112954.

55 Ahmed MZ, Ahmed O, Aibao Z, et al. Epidemic of COVID-19 in China and associated psychological problems. Asian J Psychiatr 2020;51:102092.

56 Glowacz F, Schmits E. Psychological distress during the COVID-19 lockdown: the young adults most at risk. Psychiatry Res 2020;293:113486.

57 Barber SJ, Kim H, Hyunji K. COVID-19 worries and behavior changes in older and younger men and women. J Gerontol B Psychol Sci Soc Sci 2021;76:gbaa068:e17-23. 